\title{
Formação de Professores em Comunicação Alternativa para crianças com TEA: contextos em ação
}

\author{
Liliana M. Passerino* \\ Maria Rosangela Bez** \\ Rosa Maria Vicari***
}

\section{Resumo}

O presente artigo apresenta um recorte do projeto de pesquisa SCALA - Sistema de Comunicação Alternativa para Letramento de crianças com Autismo. Nele, discutimos um aspecto importante no que se refere à formação de professores para atuarem junto a sujeitos com Transtorno do Espectro Autista (TEA) não oralizados no seu desenvolvimento sócio-cognitivo. A partir de uma visão geral da área de conhecimento denominada de Comunicação Alternativa, discute-se sua a inserção no espaço educativo para utilização com sujeitos com TEA. Aborda a questão da formação específica de professores, trazendo para discussão aspectos vinculados com a atual politica governamental na questão de formação de professores. Na sequencia, propõe-se uma abordagem sócio-histórica e cultural deste processo, a partir de contextos de ação visando uma reorganização das relações do sujeito com o mundo, e não apenas na ampliação, complementação ou suplementação das funcionalidades de comunicação do sujeito com TEA não oralizado. Finalmente, a partir do panorama traçado, apresentam-se resultados de pesquisa desenvolvida pelo grupo de pesquisa TEIAS - Tecnologia na Educação para Inclusão e Aprendizagem em Sociedade da UFRGS no âmbito do projeto SCALA. São analisadas duas propostas de formação desenvolvidas numa visão integradora que se sintetiza em três movimentos interrelacionados: problematização do fazer enquanto a ação pedagógica; pensamento em ação; e análise critica enquanto ação reflexiva.

Palavras-chave: Autismo; Transtorno do espectro autista; Formação de professores; Comunicação alternativa.

\footnotetext{
* Professora Doutora da Universidade Federal do Rio Grande do Sul, Faculdade de Educação, Departamento de Estudos Especializados. Porto Alegre, Rio Grande do Sul - Brasil.

** Professora da Universidade Federal do Rio Grande do Sul, Faculdade de Educação, Departamento de Estudos Especializados. Porto Alegre, Rio Grande do Sul - Brasil.

*** Professora Doutora da Universidade Federal do Rio Grande do Sul, Faculdade de Educação, Departamento de Estudos Especializados. Porto Alegre, Rio Grande do Sul - Brasil.
} 


\title{
Teacher training in alternative communition for children with TEA: contexts in action
}

\begin{abstract}
This article presents an excerpt of the research project SCALA (Alternative Communication System for Literacy of Children with Autism). Herein, we focus on teacher education of professionals working with nonverbal Autism Spectrum Disorder (ASD) subjects so as to foster their sociocognitive development. From an overall view of the field of Alternative Communication, we discuss its insertion and usage for educational purposes with subjects with ASD. Specific teacher education aspects are addressed considering the current government policy on teacher education programs. Then, we propose a socio-historical and cultural approach to such process from action contexts aiming at the reorganization of the relations of subjects with ASD with the world, and not simply the expansion, complementation or supplementation of the communication functionalities of nonverbal subjects with ASD. Finally, from the presented panorama, we show some outcomes research from TEIAS (Technology in Education for Inclusion and Learning in Society) research group on the scope of SCALA project. We analyze two teacher education proposals developed from an integrative view of three interrelated movements: problematization as pedagogical action; thought into action, and critical analysis as reflexive action.
\end{abstract}

Keywords: Autism; Autism spectrum disorder; Teacher education; Alternative communication.

\section{Introdução}

Iniciamos este texto a partir de uma análise do contexto atual brasileiro em termos de formação de professores e inserção de tecnologias no processo educativo. Durante décadas, o governo tem promovido projetos e programas sobre Inclusão/ Educação Especial' ${ }^{1}$ e sobre o uso de Tecnologias em sala de aula². Praticamente todas estas iniciativas estiveram acompanhada de projetos de Formação de Professores ${ }^{3}$.

Nesse processo, em 1999/2000, iniciou um programa que tentava articular tecnologias com a questão da educação especial e posteriormente com a inclusão (SANTAROSA, PASSERINO, CARNEIRO e GELLER, 2005). Mas, somente a partir de 2006 o governo brasileiro inicia uma articulação que se voltou de forma mais efetiva para a concretização de políticas públicas ao criar, por intermédio da Secretaria Especial dos Direitos Humanos da Presidência da República - SEDH/PR, o Comitê de Ajudas Técnicas - CAT (Portaria no 142). Entre os objetivos do CAT estava a criação de centros de referência; cursos de formação na área de tecnologia assistiva, e elaboração de estudos e pesquisas relacionados com o tema da tecnologia assistiva (CORDE, 2007). A partir dessa proposta se originou uma demanda por: a) compreender a Tecnologia Assistiva no âmbito educacional, já que até o momento esta 
vinculava-se mais com a área de saúde e reabilitação, e b) iniciar uma discussão sobre os processos de formação de professores especialistas ou generalistas no âmbito da educação especial para atuar nos Atendimentos Educacionais Especializados (AEE), e nas Salas de Recursos Multifuncionais (SRM).

Assim, o Ministério de Ciências e Tecnologia do Brasil em parceria com o Instituto de Tecnologia Social e o FINEP, desde 2005, vêm lançando editais para apoio financeiro a projetos de pesquisa e desenvolvimento na área de Tecnologia Asssitiva (TA $)^{4}$.

As SRM são resultado de uma política pública governamental no âmbito da inclusão escolar que inicia em 2005 com 626 salas, chegando até 15.551 salas em 2009, distribuídas em todos os estados e o Distrito Federal, atendendo aproximadamente 82\% dos municípios brasileiros (BRASIL, 2010).

O programa de Implantação de Salas de Recursos Multifuncionais visava:

apoiar os sistemas de ensino na organização e oferta do atendimento educacional especializado, por meio da implantação de salas de recursos multifuncionais nas escolas de educação básica da rede pública, fortalecendo o processo de inclusão nas classes comuns de ensino regular. (BRASIL, 2007)

Para potencializar os espaços educativos com os recursos necessários ao atendimento das necessidades educacionais de alunos com deficiência. Assim as salas foram equipadas com tecnologias e materiais didáticos diferenciados, que incluem, entre outros, recursos de Tecnologia Assistiva, com vistas a garantir igualdade de oportunidades de "acesso ao currículo e do reconhecimento das diferenças no processo educacional (PASSERINO, 2010).

Dentre as tecnologias disponíveis nas SRM encontram-se alguns recursos para a Comunicação Alternativa (CA), que consistem em sistemas para elaboração de recursos e atividades que complementem, suplementem ou forneçam alternativas para a efetivação do processo comunicativo. Existem variados sistemas de CA, com suporte tanto para baixa como para alta tecnologia, que incluem elementos de representação (fotografias, desenhos, pictogramas, etc). Seu uso fundamenta-se pelas estratégias e técnicas comunicativas utilizadas para promoção do desenvolvimento e não pelo recurso em si. Desta forma, a CA não é restrita ao recurso, senão que incluem as estratégias e técnicas que visam auxiliar no desenvolvimento de habilidades para uso intencional de símbolos linguísticos. No caso do autismo, os déficits de comunicação podem se manifestar com alterações no uso, forma ou conteúdo da linguagem em nível pragmático e semântico, e em menor medida, em nível sintático, morfossintático, fonológico ou fonético. A importância de utilizar um sistema de CA foca-se mais em processos de compreensão e produção de sentidos do que numa produção sonora ou morfosintática (PASSERINO, 2011). 
O uso da CA, especialmente para crianças com transtorno do espectro autista, inicia com os trabalhos de Walter $(1998 ; 2000)$, que adapta e padroniza o sistema PECS 5 para o Brasil. Estudos mais recentes desenvolvidos por Bez e Passerino (2009); Bez (2010); Ávila e Passerino (201lb) e Ávila (2011) envolvem o uso de comunicação alternativa com crianças com TEA a partir de propostas metodológicas que diferenciam-se do PECS. Estes estudos mostram também resultados importantes, especialmente quando apoiamos os processos de comunicação alternativa com o uso de tecnologias digitais, resultando indícios de melhorias significativas nos processos de comunicação dos sujeitos com autismo quando utilizam um sistema de comunicação alternativa como um instrumento de mediação entre os sujeitos em interação. Acreditamos que, quando a comunicação alternativa é adaptada para as necessidades de sujeitos com autismo, esta atuaria como um fator de facilitação e aproximação ao propiciar outras formas de comunicação e estabelecer, desta forma, uma "ponte" com outras pessoas (AVILA, PASSERINO, REATEGUI 2012; PASSERINO, 2012; BEZ, PASSERINO, 2012, FOSCARINI, PASSERINO, 2012; PASSERINO, BEZ, 2013; FOSCARINI, 2013; PASSERINO, 2013).

O objetivo do presente texto é apresentar os resultados do projeto SCALA (2009-2013) no que se refere à formação de professores para utilização da CA em sujeitos com TEA.

\section{Projeto SCALA: panorama da pesquisa centrada em contextos}

Desde 2009, quando se iniciou o desenvolvimento do sistema SCALA, visamos desenvolver um sistema de comunicação alternativa que incluia, não somente um programa de computador, mas uma metodologia de uso no intuito de apoiar o processo de desenvolvimento da linguagem de crianças com TEA que apresentassem déficits na comunicação oral.

A base epistemológica deste sistema é sócio-histórica, tanto na concepção como no desenvolvimento e aplicação do mesmo. Isso implica numa reorganização conceitual do processo de desenvolvimento de software conhecido como Design Centrado no Usuário (DCU) para um Desenvolvimento Centrado em Contextos de Uso (DCC) que ultrapassa a análise somente da interação sujeito-objeto e foca em processos de interação sujeito-objeto-sujeito, na qual o objeto se estabelece como instrumento de mediação. (PASSERINO, BEZ 2013; ÁVILA, PASSERINO, 2011; PASSERINO, ÁVILA e BEZ, 2010; BEZ, PASSERINO, 2009).

O sistema SCALA tem um programa de computador ${ }^{7}$ composto por três módulos: prancha, narrativas virtuais e comunicação livre ${ }^{8}$. No módulo prancha é possível construir pranchas de comunicação, no módulo narrativas visuais pode-se preparar histórias e no módulo de comunicação livre se dá a conversação através de um chat. Além de funcionalidades comuns entre os aplicativos tais como: importar imagens, editar sons, salvar, exportar, e gerenciar os diferentes arquivos gerados pelo sistema, cada módulo possui funcionalidades específicas. O menu, a esquerda, apresenta ao usuário as categorias de imagens que podem ser utilizadas em todos 
os módulos enquanto a barra horizontal de menu apresenta suas funcionalidades. Através da escolha de um layout predefinido, a pessoa pode preencher cada quadro clicando nas categorias de imagens ${ }^{9}$. Cada imagem tem uma legenda padrão que pode ser editada. Para cada quadro é possível também gravar som, ou se desejar, utilizar um sintetizador de voz que fará a leitura da legenda. O sistema prevê a inserção de imagens próprias, permitindo a personalização e adaptação ao contexto sóciohistórico do sujeito. Finalmente, a última funcionalidade desenvolvida foi a animação das ações. Tal função foi pensada a partir de pesquisas empíricas que apresentam como resultados indícios de que ações animadas podem ser mais adequadas na compreensão metafórica e simbólica de sujeitos com autismo (PASSERINO, 2005; BARTH, PASSERINO, SANTAROSA, 2007; BARAKOVA, GILLESSEN, FEIJS, 2009). A seguir apresentamos a imagem padrão dos layouts dos módulos prancha e narrativas visuais já disponíveis e do módulo comunicação livre em desenvolvimento.
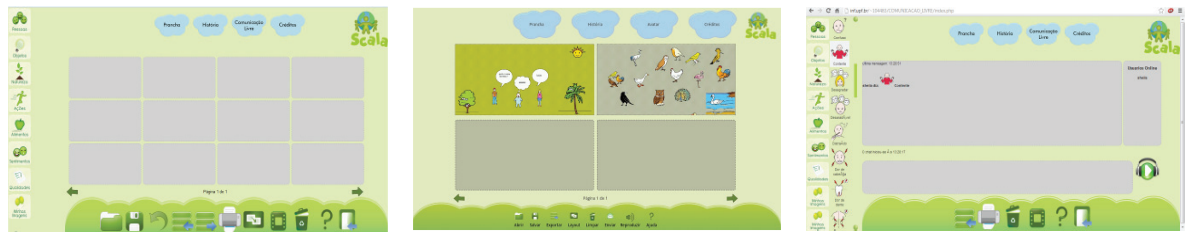

Figura 1: layout módulo prancha e módulo história ${ }^{10}$

Partindo de uma perspectiva metodológica sócio-histórica, e das premissas teóricas que norteiam o trabalho a abordagem não contempla apenas o sujeito com deficiência, mas esse sujeito em interação com os outros, o que amplia os focos de investigação para: (a) os contextos sociais nos quais (b) práticas culturais de comunicação e letramento são desenvolvidas pelos (c) diferentes participantes, por meio de (d) ações mediadoras. Assim, as diretrizes gerais do DCC consideram este contexto macro do desenvolvimento humano na interação social como base para a análise dos casos sem isolar as características e necessidades dos sujeitos de seus contextos. Esta diferença é para evitar o que, em geral, acontece no desenvolvimento de Tecnologia Assistiva, que se centra numa visão funcional do ser humano. A proposta do sistema não é ignorar os aspectos funcionais, mas, considerar estes dentro do âmbito cultural no qual o individuo está inserido, visando preferencialmente, sua ampliação . Desta forma, o foco sempre é o sujeito em relação com seus diferentes contextos, num processo de mediação, que vai da aprendizagem ao desenvolvimento humano (VYGOTSKY, 1988). Cada contexto configura nossas relações, portanto as mediações possíveis" ${ }^{11}$ numa dimensão espaço-temporal ${ }^{12}$ (PASSERINO, BEZ, 2013). A configuração de contextos atravessa a pesquisa sóciohistórica, e constitui o nível macro de investigação necessário para a compreensão do fenômeno da comunicação dentro do espaço educativo. Num nível micro, as tríades sujeito-mediador, sujeito-não-oralizado e ações mediadoras ${ }^{13}$ são o ponto de partida para compreensão dos processos de mediação com tecnologias, no caso o SCALA, e auxilia no desenvolvimento de recursos tecnológicos como o SCALA de forma diferenciada. Dito de outra forma, o que as pessoas fazem em diferentes contextos, com diferentes objetivos e cenários é o guia o desenvolvimento do sistema. 
No caso desse artigo, nosso recorte centra-se no cenário educativo da relação professor-sistema-aluno enquanto processo de formação. Antes de apresentar os dados, estabeleceremos as premissas necessárias para compreender como a comunicação é concebida na epistemologia sócio-histórica e na relação com o Autismo e, finalmente, como a formação de professores generalistas ou especialistas, proposta na maioria das formações atuais, não atende, na nossa opinião, as necessidades de formação e de atuação em sala de aula.

\section{Transtorno do Espectro Autista e Comunicação: a Comunicação Alternativa como mediadora do desenvolviménto}

O autismo, a partir da DSM-5 $5^{14}$, é uma das síndromes pertencentes à categoria denominada Transtornos de Neurodesenvolvimento, em uma categoria específica com o nome de Transtornos do Espectro Autista, e que inclui, além do transtorno autista (autismo), o transtorno de Asperger, o transtorno desintegrativo da infância e os transtornos invasivos do desenvolvimento sem outra especificação.

Assim, segundo a DSM-5 o Transtorno do Espectro Autista é um distúrbio do desenvolvimento neurológico e deve estar presente desde a infância ou do início da infância, apresentando déficits em dois âmbitos, o social/comunicativo e o comportamental (APA, 2013). No presente artigo, a ênfase será sobre o aspecto de Linguagem e Comunicação que apesar de contar com muitos estudos recentes ${ }^{15}$, ainda existe uma lacuna nessa temática que, ao longo das últimas décadas, se voltou mais à interação social, diagnóstico e prevalência. Os déficits de comunicação, no autismo, como ausência de intercâmbios corporais expressivos (na comunicação não verbal), falhas nos intercâmbios coloquiais e falas não ajustadas ao contexto (na comunicação verbal) são registrados na literatura (JORDAN; POWELL, 1995). Um estudo realizado com crianças com autismo, crianças normais e deficientes mentais Peeters (1998) analisou os tipos de gestos que as crianças produzem para se comunicar e evidenciou que, enquanto as crianças normais e com deficiência mental utilizavam todos os tipos de gestos, o grupo de crianças com autismo utilizava somente gestos dêiticos e instrumentais. Outros estudos, desenvolvidos nas últimas décadas, confirmaram também dificuldades em utilizar marcadores pragmáticos de tempo e espaço (BRUNER;FELDMAN, 1993; LOVELAND; TUNALI, 1993), assim como expressões de estados mentais (BARON-COHEN, 1988; 1990) uso de expressões e gestos inadequados (LOVELAND, MCEVOY; KELLEY, 1990), e uma diminuição da complexidade e número de declarações do tipo "se-então" (TAGER-FLUSBERG; SULLIVAN, 1995).

Existem também déficits na pragmática da comunicação que pesquisadores (BARON-COHEN, 1988, 1989, 1990; BRUNER; FELDMAN, 1993; TAGER-FLUSBERG; SULLIVAN, 1995; HAPPÉ, 1994), têm identificado com possíveis déficits na teoria da mente uma vez que, segundo as pesquisas, tanto sobre as competências linguísticas, quanto as sociocognitivas, existiria um déficit na leitura da mente em pessoas com autismo que afetaria a capacidade de atribuir estados mentais, compreender intenções, crenças e emoções de outras pessoas. Por 
outro lado, outras pesquisas parecem apontar a que os problemas de comunicação poderiam estar associados à atenção conjunta (TOMASELLO, 2003) ou imitação mútua (MELTZOFF; GOPNIK, 1993).

Em termos parecidos com a pesquisa no Sistema SCALA (CIHAK, 2007), desenvolveu um estudo com três crianças com autismo entre 7 e 9 anos, visando identificar a compreensão simbólica de imagens, a partir da comunicação funcional ${ }^{16}$. Nesse estudo, as crianças não eram oralizadas e não utilizavam nenhum tipo de comunicação visual/simbólica. Os sujeitos foram submetidos a um processo de alfabetização sistemática visual, que consistiu em compreender familiares, pessoas, objetos, ações e sequências. Cada categoria era composta por um conjunto de dez símbolos (ou fotografias). A proposta de intervenção mostrou-se efetiva após nove semanas de intervenção utilizando as imagens com sucesso para comunicar pedidos, definir tarefas entre outras ações comunicativas.

Assim, os déficits na comunicação e no desenvolvimento da linguagem, presentes no autismo, variam desde a ausência da fala até a fala hiperformal. No caso da ausência da comunicação verbal, há uma falta de intercâmbios corporais expressivos e, quando há comunicação verbal, há carência nos intercâmbios da conversação. Isso leva a uma sensação de privação de contato afetivo com a pessoa com autismo (HOBSON, 1993). Para Bara et al. (2001): a competência comunicativa estaria vinculada à habilidade de utilizar a linguagem como um instrumento de efetiva interação em contextos sociais.

Contrariando alguns autores, segundo os quais o comportamento estereotipado não tem um maior significado, para Molini (2001) há presença da intenção comunicativa nesses comportamentos. $\mathrm{O}$ mesmo foi evidenciado na pesquisa com pessoas com autismo realizada por Passerino (2005), a partir da análise da intencionalidade de comunicação quando mediada por tecnologias.

No que se refere ao desenvolvimento da linguagem funcional e comunicativa, Fernandes; Neves e Rafael (2009) ressaltam que 35\% a 45\% das crianças com autismo não chegam a desenvolvê-la, porém a falta de linguagem não é vinculada a uma incapacidade de pronunciar palavras ou na construção de sentenças, mas pelos aspectos semânticos da linguagem, na compreensão dos significados das palavras e na sua utilização social.

Nesse sentido, como mencionado antes, Sistemas de CA podem ser uma "ponte" na comunicação humana, ao se constituírem como instrumentos de mediação. Porém, cabe destacar que tal "ponte" não se sustenta meramente na tecnologia, senão que é necessário que o recurso seja bem alicerçado numa metodologia alinhada com a perspectiva teórica que contribua no processo de desenvolvimento da linguagem. Assim, sistemas de CA e, em particular, o sistema SCALA são compostos por elementos tecnológicos, humanos e sociais que se imbricam para constituir uma totalidade inter-relacionada, o que se evidencia na fala da pesquisadora que afirma "[...] mais importante que [...] qualquer recurso utilizado para intermediar o diálogo, é o tempo, a escuta e a dedicação que dispensamos ao outro" (WALTER, 2011, p. 139). 
No viés específico de pesquisa (Comunicação Alternativa, Tecnologia e Autismo), poucos são os estudos sobre dispositivos móveis para comunicação alternativa que focam pessoas com esta síndrome. Na revisão de literatura, além do SCALA, identificaram-se pesquisas de (RODRÍGUEZ-FÓRTIZ, FERNÁNDEZLOPEZ, RODRIGUEZ, 20l1) com o sistema Sc@ut. O Sc@ut é um sistema de comunicação alternativa, que foi adaptado para ser um comunicador para Pocket PCs e Nintendo DS. Segundo os autores, o uso do sistema em grupos de crianças com autismo mostrou uma melhoria no comportamento dos sujeitos, na linguagem oral. Em alguns dos sujeitos, os modelos de comunicação previstos, no sistema, foram usados para treinar habilidades sociais e da vida cotidiana (RODRÍGUEZ-FÓRTIZ, GONZẢLEZ, FERNÁNDEZ, 2009). Já Herbert (2010) e Ipads for Learning (2011) utilizaram o Proloquo2Go para criação de histórias personalizadas para demonstrar sinais pessoais e ensinar mensagens sociais com resultados de evolução de palavras para frases, com a interação dos alunos e o aplicativo.

Qual a dificuldade que enfrentam essas pesquisas? O ponto crucial é a concepção da comunicação humana e o recorte realizado em alguns estudos sobre Autismo. Antes de prosseguir, cabe trazermos, rapidamente, algumas considerações sobre o Transtorno do Espectro Autista e a comunicação neste âmbito. Tratando-se do autismo, as falhas na comunicação podem se apresentar com alterações no uso, forma ou conteúdo da linguagem em nível pragmático, e em menor medida em nível sintático, morfossintático, fonológico ou fonético, assim a importância de utilizar um sistema de CA foca-se mais em processos de compreensão e produção, estando ambas situações inter-relacionadas (PASSERINO, 2011).

Seguindo, destacamos pesquisas com a utilização de CA e tecnologia digitais. Estes estudos indicam melhorias significativas nos processos de comunicação, seja na enunciação, seja na pragmática da mesma, dos sujeitos com autismo, quando utilizado algum sistema de comunicação alternativa que atua como um instrumento de mediação entre os sujeitos em interação. Demonstrando que, quando a CA é adaptada com o intuito de sanar as necessidades do sujeito com autismo, proporciona outras formas de comunicação e cria um elo com as outras pessoas (BEZ; PASSERINO, 2009; BEZ, 2010; ÁVILA; PASSERINO, 2011).

Sob este enfoque sistemas de CA atuariam como um elo para comunicação para sujeitos com autismo, enfatizando-se que o recurso de CA precisa ser claramente alicerçado a uma metodologia epistemologicamente embasada, não meramente na tecnologia. Concordando com Walter (2011) os sistemas de CA são uma totalidade entrelaçada de elementos técnológicos, humanos e sociais e, em termos de formação, propomos uma problematização e reflexão de nossa prática com uso do sistema SCALA com professores e alunos em diferentes contextos.

\section{Formação de Professores em Contextos: proposta do SCALA}

A partir da implantação das SRM, a Comunicação Alternativa teve recursos para seu uso através de software e outros materiais, e formações de professores 
relacionados com o AEE foram promovidos pelo $\mathrm{MEC}^{17}$. Mas, sua utilização ainda é incipiente, principalmente se considerarmos o professor de sala de aula atual, como aponta a pesquisa de Scheneider e Passerino (2010), cujos resultados mostram que a comunidade escolar, em geral, desconhece os materiais disponíveis nas salas de recursos, pelos motivos mais diversos (falta de informação, desinteresse, entre outros).

$\mathrm{Na}$ maioria dos casos, os professores se interessam em conhecer apenas quando um aluno com deficiência é incluído na sua sala. Este fato mostra que, por um lado, a formação inicial de professores não atende às necessidades de formação necessárias para que estes saibam como proceder com a diversidade em sala de aula. Por outro lado, evidencia um paradigma subjacente ainda na prática inclusiva de que a tecnologia assistiva pertence ao sujeito com deficiência. Porém, numa perspectiva sócio-histórica, a tecnologia assistiva não podem ser consideradas a partir da individualidade do sujeito, mas da sua participação em práticas culturais potencializadas a partir de tais tecnologias. Desta forma, as práticas mediadas por tecnologias reorganizam as relações do sujeito com o social, ultrapassando a questão meramente funcional, potencializando sua atuação e inserção (PASSERINO, 2010).

Pelo exposto, percebe-se a complexidade de uma formação de professores que evite reducionismos tecnológicos, com formações instrumentalizadoras e descontextualizadas, ou formações teóricas que idealizam situações de sala de aula e dissociam o binômio teoria-prática (CANDAU; LELIS, 1999). Como afirma Tardif (2007) devemos potencializar o "saber docente" "[...] um saber plural, formado pelo amálgama, mais ou menos coerente, de saberes oriundos da formação profissional e de saberes disciplinares, curriculares e experienciais". (p. 36).

A seguir, apresentamos um recorte do projeto SCALA relacionada com a formação de professores, no qual se buscou atender a complexidade mencionada, visando uma formação não generalista e focada no contexto de atuação dos professores.

Em 2012, foram realizadas diversas formações envolvendo a rede pública municipal e a rede privada. No presente artigo, apresentam-se apenas duas formações tendo como público-alvo professores especialistas em Educação Especial e professores de sala de aula. As formações buscaram abordar sobre o uso da comunicação alternativa como instrumento de mediação no letramento de crianças com autismo. Ambas formações se desenvolveram na modalidade semipresencial, com apoio de recursos digitais ${ }^{18}$, sendo que a formação na rede pública teve como foco o processo de inclusão de alunos com autismo na rede regular, com mais de 80 horas de estudos, das quais participaram 40 professores da rede pública municipal de Alegrete/RS. Nela, contemplamos a abordagem do Desenvolvimento Centrado em Contextos a partir da construção de um portfólio digital com videoconferências semanais e encontros presencias mensais. A proposta discutia a Teoria Sócio-histórica como viés epistêmico-metodológico para uma abordagem sistêmica do autismo, procurando capacitar o professor para identificar necessidades e potencialidades dos seus alunos e planejar o uso de recursos para intervenção pedagógica com ênfase nas tecnologias, especialmente as de comunicação alternativa. A proposta metodológica calcou-se no 
estudo de caso, assim, desde os primeiros encontros, os professores foram desafiados a selecionar um caso de sujeito com TEA, incluído na escola, para acompanhar ao longo da formação. Diversos protocolos de observação e registro foram organizados para orientar a análise e identificação de necessidades e potencialidades do caso em questão. Os professores, livremente, optaram por trabalhar de forma individual ou em grupo e foram instigados a mapear os diferentes contextos nos quais o aluno habita (família, AEE, sala de aula, outros espaços e tempos). A observação permitiu elaborar um perfil sócio-histórico do sujeito identificando necessidades e potencialidades na comunicação (quadro l).

\begin{tabular}{|c|c|c|c|}
\hline Comunicação & Interação & Identificação & Potencialidades \\
\hline $\begin{array}{l}\text { Pela fala? Como é sua } \\
\text { oralização? } \\
\text { Por gestos? Quais? } \\
\text { Pelo olhar? De que forma? } \\
\text { Através de algum sistema de } \\
\text { comunicação alternativa? } \\
\text { Quando o sujeito se comunica? } \\
\text { Qual a finalidade desta } \\
\text { comunicação. } \\
\text { Para satisfazer seus desejos? } \\
\text { Ou Para que? O que ele } \\
\text { comunica } \\
\text { É compreensível o que ele } \\
\text { deseja comunicar } \\
\text { O faz através de estereotipias } \\
\text { Ocorre de forma espontânea } \\
\text { Qual o tempo de duração desta } \\
\text { comunicação }\end{array}$ & $\begin{array}{l}\text { Como ele } \\
\text { interage } \\
\text { Com o que } \\
\text { (objetos) } \\
\text { Com quem } \\
\text { (pessoas) } \\
\text { Quando ele } \\
\text { interage } \\
\text { Ocorre } \\
\text { de forma } \\
\text { espontânea } \\
\text { Qual o } \\
\text { tempo de } \\
\text { duração desta } \\
\text { comunicação }\end{array}$ & $\begin{array}{l}\text { Procura } \\
\text { descobrir como } \\
\text { é o sujeito } \\
\text { aos olhos de } \\
\text { diferentes } \\
\text { pessoas - } \\
\text { familiares, } \\
\text { professores, } \\
\text { auxiliar escolar. }\end{array}$ & $\begin{array}{l}\text { Quais suas } \\
\text { potencialidades? } \\
\text { O que ele gosta de } \\
\text { aprender? } \\
\text { Quais suas } \\
\text { preferências? (o que } \\
\text { gosta) } \\
\text { Quais suas } \\
\text { necessidades? } \\
\text { Tem algum tipo de } \\
\text { comportamento } \\
\text { específico? - em que } \\
\text { momento aparece? } \\
\text { há algum tipo de } \\
\text { intencionalidade } \\
\text { nele? qual? }\end{array}$ \\
\hline
\end{tabular}

Quadro 1 - Protocolo de Observação

A questão dos contextos culturais, que cada sujeito habita, seus elementos constitutivos e as questões metodológicas para constituição dos mesmos, foram ponto de discussão e análise com o grupo e permitiu a elaboração de um contexto sócio-histórico do aluno escolhido (figura 2) 

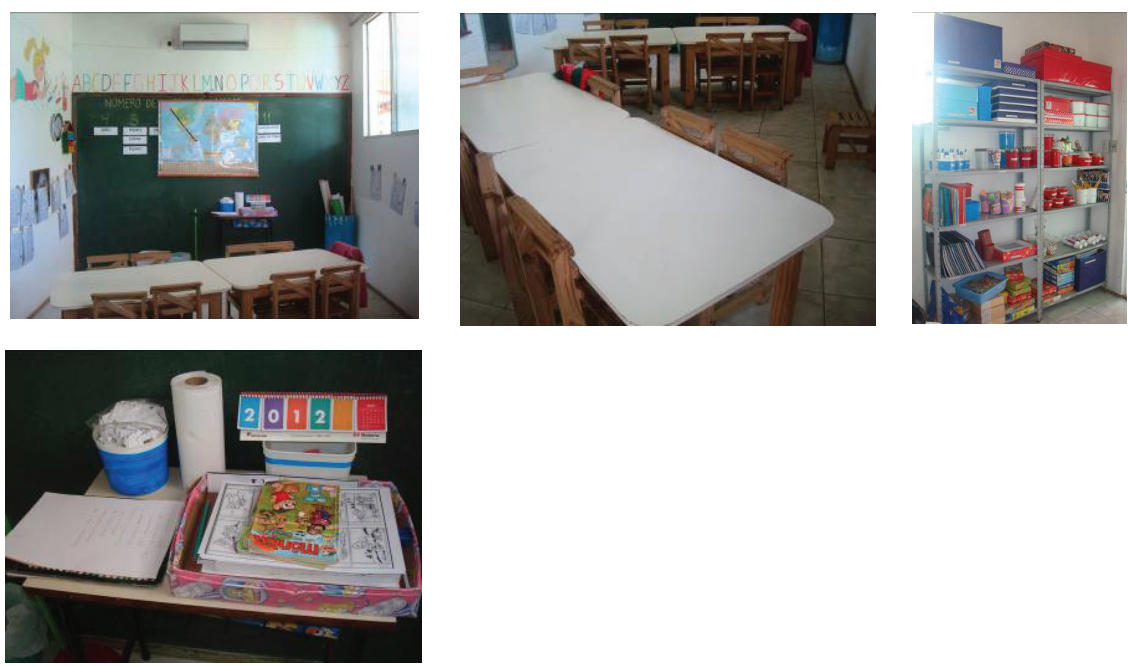

Figura 2 - Exemplo de Contexto Sócio-histórico elaborado

Para apoiar o processo de planejamento e intervenção, partindo do contexto sócio-histórico elaborado, foram apresentados diversos recursos de TA, compreendendo tais recursos enquanto instrumentos de mediação (signos) para o desenvolvimento do sujeito em interação com seu contexto. Ou seja, os recursos não eram apenas pensados "para o sujeito" e sim para a turma, e como este recurso poderia potencializar a interação e comunicação desse sujeito, levando-o a uma nova Zona de Desenvolvimento Potencial (VYGOTSKY, 1998).

A proposta metodológica proporcionou condições para elaboração de intervenções através de ações mediadoras. Como por exemplo para o caso de:

Aluno 4 anos, comunica-se através de gestos, não contempla linguagem expressiva, ou seja, quando necessita de algo aponta o objeto ou segura a pessoa pela mão até alcançar o seu objetivo. Apresenta interesse por atividades no pátio, objetos circulares (bola ou globo terrestre) e folhear livros ou revistas. Raramente interage com colegas, professores ou funcionários, porém elege alguém o qual satisfaça seus desejos. Foi conseguido algumas regras de comportamento.

Os casos foram discutidos em grupo e o planejamento sofria críticas e sugestões, mantendo sempre o foco no desenvolvimento do sujeito. Os professores realizaram as intervenções e seus resultados foram, também, compartilhados com o grupo e analisados dentro do contexto da formação. Dentre os resultados apresentados pelos professores está o despertar pela leitura, ampliação da coordenação fina dos alunos, aumento da concentração, interação e tempo em uma atividade, ampliação da comunicação e na participação de ações do seu cotidiano. 
A segunda formação teve um foco mais restrito, mas manteve a proposta de estudo de caso. Desenvolveu-se com quatro professores de duas escolas de educação infantil da rede privada, escolhidas intencionalmente por possuírem, em sua sala de aula, caso de inclusão de sujeito com autismo. Os alunos, com déficit na oralização, tiveram como principal foco o uso da comunicação alternativa como potencializadora. Assim como na formação anterior, os conteúdos foram disponibilizados num ambiente virtual colaborativol9 com encontros presenciais mensais e com o objetivo capacitar professores para identificar e planejar o uso de recursos para intervenção para alunos com Autismo, com ênfase na comunicação alternativa.

As professoras foram orientadas a elaborarem o perfil sócio-histórico dos alunos, sociograma e perfil do contexto da sala de aula. Com a montagem e análise dos perfis elaborados, foram estruturadas ações mediadoras em conjunto, e estas, após as intervenções, relatavam seus resultados e traziam novos questionamentos a serem pensados, assim novas estratégias de intervenções eram estruturadas. Houve grande participação dos professores, tanto de relatos do desenvolvimento dos alunos, como de suas angústias e dificuldades nos problemas novos que surgiam no decorrer de cada encontro.

O sistema de comunicação alternativa SCALA foi utilizado de forma direta ou indireta em todas as intervenções, individualmente pelo aluno e com toda a turma, como por exemplo, na narração elaborada pelos próprios alunos da turma da educação infantil, retratados na figura 3
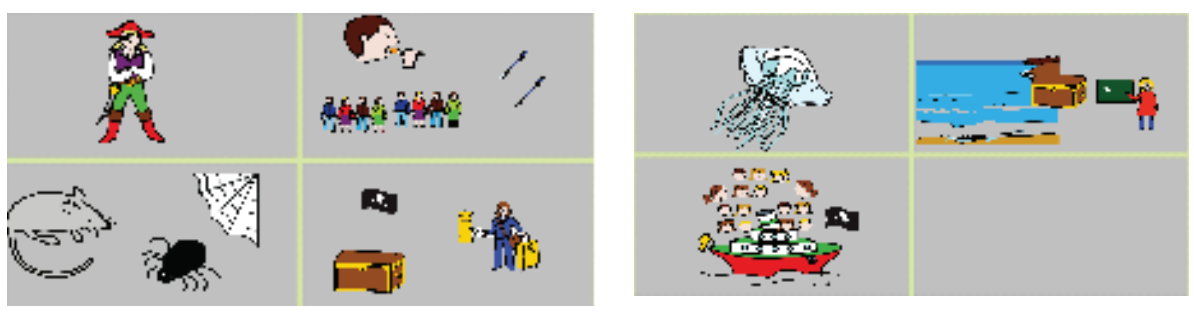

Figura 3 - Exemplo de uso do SCALA com a turma para construção de histórias

Narração elaborada pelos próprios alunos da turma da educação infantil para a história criada:

A incrível história da turma que virou pirata. Era uma vez uma meleca que se enlouqueceu e comia as pessoas... E até as canetas. Um dia, ela encontrou uma aranha gigante e um rato mais gigante ainda; e, nesse momento ela se explodiu de susto e melecou todo mundo. E todos engoliram um pouco de gosma. Só o carteiro, que se chamava jorge amado, é que não engoliu a gosma. Ele era muito sabido. Como ele não tinha engulido a gosma do mal, ele trouxe uma água milagrosa pra todos os engosmentados tomarem. Ai eles conseguiram cuspir aquela gosma nojenta e ficaram curados. O carteiro resolveu dar 
um presentinho pra todos: um baú de pirata cheio de coisas gostosas e de brinquedos... Mas, de repente, de dentro do baú apareceu uma água viva bem maluca. Quando ela tocava na gente, a gente se queimava... Mas só um pouquinho... E de dentro dela apareceu um mapa.... Que era de um tesouro... Do pirata encantado!!! Todos da turma foram pro fundo do mar atrás do tesouro... Até as profes. Quando o tesouro foi encontrado, foi levado pro barco e a turma toda virou uma turma de piratas que viveu feliz pra sempre viajando pelos mares... Fim.

As formações apresentadas levaram em conta tanto o sujeito como os contextos, e exigiu de um grande envolvimento dos formadores não na preparação de conteúdo, mas no acompanhamento e seleção de recursos e materiais que apoiassem uma formação mais aberta, não centrada em conteúdo e sim na relação contextosujeito.

\section{Considerações finais: alguns desdobramentos e desafios na formação}

Uma vez que sujeitos com TEA apresentam uma grande diversidade de potencialidades e limitações nas questões que se referem à interação social e comunicação, as formações privilegiaram muito mais a compreensão do fenômeno e o diagnóstico pró-ativo de possibilidades em termos de estratégias e recursos, que de fato um conteúdo definido a priori. Assim, o foco em cada contexto, e suas peculiaridades únicas, permitiu uma formação específica e a transposição e generalização foi promovida pelo intercâmbio entre o grupo e pelas reflexões provocadas ao longo de encontros e análise de dados. Assim, foi possível elaborar estratégias de planejamento e intervenção com ações mediadoras que articulavam recursos e sujeitos em interação visando ao desenvolvimento dos alunos com autismo.

Ao se analisar as duas propostas de formação, desenvolvidas numa visão integrada, é possível identificar três movimentos inter-relacionados, problematização do fazer enquanto a ação pedagógica; pensamento em ação, enquanto ação consciente e intencional a partir de uma problematização inicial que não é isolada do contexto de atuação de cada sujeito e, finalmente, a análise crítica enquanto ação reflexiva, que promove o recomeço dos processos anteriores.

Assim, a estrutura do curso de formação orientou a prática do professor a partir de uma realidade sócio-histórica, sendo que a escolha dos recursos, entre eles o Sistema SCALA, não fica restrita a um sujeito, mas aos contextos de interação. Desta forma, cada formação foi pensada na temporalidade da ação e na complexidade do contexto sócio-histórico. 
Foi possível constatar que a formação com uma proposta centrada em contextos a partir de ações mediadoras potencializaram a apropriação dos professores da tecnologia assistiva e uma melhor compreensão das possibilidades de desenvolvimento dos sujeitos e da inclusão. Tudo isso pode ser verificado através do relato das professoras, ao afirmarem que o curso foi muito além do conhecimento teórico a respeito do autismo, levou realmente a prática para inclusão do aluno. Trouxe conhecimento do SCALA para ser usado com a turma toda, revelando-se um potente recurso de alfabetização, pois, "A troca de experiência entre os professores fez com que nos sentíssemos mais seguras, vimos que não estávamos sozinhas"(professora Patricia).

Podemos perceber, através destas formações e de outras já realizadas pelo grupo TEIAS, a importância da capacitação do professor para o uso das tecnologias assistivas como recursos potecializador para a efetiva inclusão dos alunos com TEA e como a metodologia de ações mediadoras e do DCC trás possibilidades do uso de atividades que envolvam a turma toda e, não somente foquem no sujeito. No caso específico do SCALA, mostrou-se efetivo como recurso de desenvolvimento de sujeitos com TEA.

\section{Referências}

APA- Associação Americana de Psiquiatria. DSM-V - Diagnostic and Statistic Manual of Mental Disorders, 2013.

AVILA, B. G; PASSERINO, L. M. Comunicação Aumentativa e Alternativa e Autismo: desenvolvendo estratégias por meio do SCALA. In: Anais VI Seminário Nacional de Pesquisa em Educação especial: práticas pedagógicas na educação especial: multiplicidade do atendimento educacional especializado, v. 1. p. 1-10, 2011.

AVILA, B. G. Comunicação aumentativa e alternativa para o desenvolvimento da oralidade de pessoas com autismo. Dissertação. Faculdade de Educação. Programa de Pós-Graduação em Educação. UFRGS. Porto Alegre: 2011.

AVILA, B. G. ; PASSERINO, L. M. ; REATEGUI, E. Proposta de uma metodologia para a construção de um sistema de CAA focado no contexto de seus usuários. Revista Brasileira de Informática na Educação, v. 20, p. 87-96, 2012.

BARA, G. B.; BUCCIARELLI, M.; COLLE, L. Communicative abilities in autism: evidence for attencional deficits. Brain and language, v. 77, p. 216-240, 2001.

BARAKOVA, E.; GILLESSEN, J.; FEIJS, L. Social training of autistic children with interactive intelligent agents. Journal of Integrative Neuroscience, v. 8, n. 1, p. 23-34, 2009.

BARON-Cohen, S. Autismo: uma alteração cognitiva específica de "cegueira mental". Revista Portuguesa de Pedagogia, Ano XXIV, 1990, p.407-430.

BARON-Cohen, S. Perceptual role taking and protodeclarative pointing in autism. British Journal of Developmental Psychology, 1989, 7, 113-127.

BARON-Cohen, S. Without a theory of mind one cannot participate in a conversation. Cognition, v. 29, p. 83-84, 1988. 
BARTH, C; PASSERINO, L.M.; SANTAROSA, L. M. C. Descobrindo emoções: software para estudo da teoria da mente em sujeitos com autismo. CINTED. Porto Alegre, v.3, n.1, 2005. Disponível em: 〈http://www.cinted.ufrgs.br/〉. Acesso em: 20 de mai. 2007.

BEZ, M. R. ; PASSERINO, L. M. Avaliação e acompanhamento do desenvolvimento de sujeitos com Transtornos Globais do Desenvolvimento através do uso de inventários. RETEME Revista de Tecnologias e Mídias na Educação, v. 2, p. 60-79, 2012.

BEZ, M. R. Comunicação aumentativa e alternativa para sujeitos com Transtornos Globais do Desenvolvimento na promoção da expressão e intencionalidade por meio de Ações Mediadoras. Dissertação. Programa de Pós-Graduação em Educação - Faculdade de Educação. Universidade Federal Do Rio Grande Do Sul. Porto Alegre, 2010.

BEZ, M. R.; PASSERINO, L. M. Applying Alternative and Augmentative Communication to an inclusive group. In: WCCE 2009 - Education and Technology for a Better World Monday, 2009, Bento Gonçalves. WCCE 2009. Proceedings - Education and Technology for a Better World Monday. Germany : IFIP WCCE, v. 1. p. 164-174, 2009.

BEZ, M. R.; PASSERINO, L. M.; SCALA 2.0: software de comunicação alternativa para web. Revista Avances Investigación en Ingeniería, v. 9, p. 120-127, 2012.

BRASIL. Ministerio da Educação, Secretaria de Educação Especial. Edital № 01 de 26 de abril de 2007.PROGRAMA DE IMPLANTAÇÃO DE SALAS DE RECURSOS MULTIFUNCIONAI. Disponível em: 〈http://portal.mec.gov.br/arquivos/pdf/2007_salas.pdf〉Acesso em: 20 abr. 2013.

BRUNER, J., \& FELDMAN, C. Theory of mind and the problem of autism. In S. Baron-Cohen, H. Tager-Flsberg \& D. Cohen (Eds.), Understanding other minds: Perspectives from autism. Oxford: Oxford University Press, 1993.

CANDAU, V. M. F.; LELIS, I. A. A relação teoria-prática na formação do educador. In: CANDAU, V. M. F. (org.). Rumo a uma nova didática. 9. ed. Petrópolis: Vozes, 1999, p. 56-72.

CIHAK, D. Teaching students with autism to read pictures. Research in: Autism Spectrum Disorders 1, 2007, p. 318-329.

CORDE. COMITÊ DE AJUDAS TÉCNICAS, CAT, Secretaria Especial dos Direitos Humanos da Presidência da República (CORDE/SEDH/PR), Brasília, 2007, Ata da Reunião VII, Disponível em:〈http://www.mj.gov.br/corde/arquivos/doc/Ata_VII_Reunião_do_Comite_de_ Ajudas_Técnicas.doc». Acesso em: 13 de jul. de 2010.

FERNANDES, A. V.; NEVES, J. V. A.; RAFAEL A. Autismo. Instituto de Computação Universidade Estadual de Campinas. Disponível em: 〈www.ic.unicamp.br/ -wainer/cursos/906/ trabalhos/autismo.pdf>. Acesso em: abr. de 2009.

FOSCARINI, A. C. ; PASSERINO, L. M. Mediação e Desenvolvimento no Atendimento Educacional Especializado através do uso de artefatos tecnológicos. In: ANPED SUL Seminário de Pesquisa em Educação da Região Sul - A Pós-Graduação e suas interlocuções com a Educação Básica, 2012, caxias do Sul/RS. X ANPED SUL Seminário de Pesquisa em Educação da Região Sul - A Pós-Graduação e suas interlocuções com a Educação Básica, v. 1. p. 1-15, 2012. 
FOSCARINI, A. C. A intencionalidade de comunicação mediada em autismo: um estudo de aquisição de gestos no sistema SCALA. Programa de Pós-Graduação em Educação - Faculdade de Educação. Universidade Federal Do Rio Grande Do Sul. Porto Alegre, 2013.

HAPPÉ, F. An advance test of theory of mind: understanding of story characters' thoughts and feeling by able autistic, mentally handicapped, and normal children and adults. Journal f Autism and Development Disorders, v. 24, p. 129-154, 1994.

HERBERT, M. The iPad - Breaking New Ground in Special Education. District Administration: New and Noteworthy, 2010.

HOBSON, P. Understanding persons: The role of affect. Em S. Ba. ron-Cohen, H. TagerFlusberg \& D. J. Cohen (Orgs.), Understanding other minds: Perspectives from autism, 1993 p. 205-227. Oxford: Oxford Medical Publications.

IPADS FOR LEARNING. iPads for Education | Case Studies | Warringa Park School. SCIRUS: Elsevier, 2011.

JORDAN, R.; POWELL, S. Understanding and Teaching Children with Autism. West Sussex, England: John Wiley\&eSons, 1995

LOVELAND, K.; TUNALI, B. Narrative language in autism and the theory of mind hypothesis: awider perspective. In S. Baron-Cohen, H. Tager-Flusberg, and D. Cohen(Eds.), Understanding other minds: Perspectives from autism, pp. 247-266, Oxford University Press, 1993.

LOVELAND, K. A.; MCEVOY, R. E.; TUNALI, B.; KELLEY, M. L. Narrative story telling in autism and Down's syndrome. British Journal of Developmental Psychology, 1990, 8, 9-23.

MELTZOFF, A. N.; GOPNIK, A. The role of imitation in understanding persons and developing a theory of mind. In: S. Baron-Cohen, H. Tager-Flusberg, \& D. J. Cohen (Eds), Understanding other minds. Oxford Medical Publications, 1993, p. 335-366.

MOLINI, D. R. Verificação de diferentes modelos de coleta de dados dos aspectos sociocognitivos na terapia fonoaudiológica de crianças com distúrbios psiquiátricos. 2001. 230f. Dissertação (Mestrado em Ciências) - Universidade de São Paulo, São Paulo, 2001.

ORRÚ, S. E. A constituição da linguagem de alunos autistas apoiada em Comunicação Suplementar Alternativa. Tese de Doutorado. Piracicaba: UNIMEP, 2006.

PASSERINO, L. M. Apontamentos para uma reflexão sobre a função social das tecnologias no processo educativo. Texto Digital (UERJ), v. 6, p. 1-20, 2010.

PASSERINO, L. M.; BEZ, M. R. Building an Alternative Communication System for Literacy of Children with Autism (SCALA) with Context-Centered Design of Usage. In: Autism / Book 1. v. 1 p. 655-679, 2013. 〈http://dx.doi.org/10.5772/54547〉

PASSERINO, L. M. A Comunicação aumentativa e alternativa no espaço do atendimento educacional especializado: trajetórias imbricadas de investigação e desenvolvimento tecnológico. In: Anais VI Seminário Nacional de Pesquisa em Educação Especial: práticas pedagógicas na educação especial: multiplicidade do atendimento educacional especializado, 2011. v. 1. p. 1-17. 
PASSERINO, L. M. Pessoas com autismo em ambientes digitais de aprendizagem: estudo dos processos de interação social e mediação. 2005. Universidade Federal do Rio Grande do Sul. Faculdade de Educação. Programa de Pós-Graduação em Informática na Educação. Disponível em 〈http://hdl.handle.net/10183/13081〉.

PASSERINO, L. M.; AVILA, B. G.; BEZ, M. R. SCALA: Um sistema de comunicação alternativa para o letramento de pessoas com Autismo. RENOTE. Revista Novas Tecnologias na Educação, v. 1, p. 1-10, 2010.

PASSERINO, L. M. Anjos Tecnológicos na Torre de Babel: reflexões sobre o uso da comunicação alternativa em dispositivos móveis. In: Maria Claudia Brito;Andréa Regina Nunes Misquiatti. (Org.). TRANSTORNOS DO ESPECTRO DO AUTISMO E FONOAUDIOLOGIA: atualização multiprofissional em saúde e educação. led.Curitiba: EDITORA CRV, v. 1, p. 209228, 2012.

PASSERINO, L. M. Comunicação alternativa, autismo e tecnologia: estudos de caso a partir do Scala. In: Theresinha Guimarães Miranda; Teófilo Alves Galvão Filho. (Org.). O professor e a educação inclusiva: formação, práticas e lugares. led.Salvador/BA: Editora da Universidade Federal da Bahia, 2012, v. 1, p. 217-240.

PEETERS, T. Autism: From Theoretical Understanding to Educational Intervention. Whurr Publishers, 1998.

RODRÍGUEZ-Fórtiz, M. J., Fernández-Lopez, A., Rodriguez, M. L. Mobile Communication and Learning Applications for Autistic People. In: Williams, Tim (Ed.) Autism Spectrum Disorders - From Genes to Environment. Rieka, Croatia: Intechweb.org, 2011, p. 349-362.

RODRÍGUEZ-Fórtiz, M. J., González, J. L., Fernández, A., Entrena, M., Hornos, M. J., Pérez, A., Carrillo, A. \& Barragán, L. "Sc@ut: Developing Adapted Communicators for Special Education. Procedia - Social and Behavioral Sciences, 1 (1), p. 1348-1352. Elsevier, 2009.

SANTAROSA, L. C.; PASSERINO, L. M.; CARNEIRO, M. L.; GELLER, M. Formação de professores a distância e em serviço através de ambientes digitais - a vivência do Proinesp. RENOTE, v. 3, n. 2, 2005.

SCHNEIDER, F. C. ; PASSERINO, L. M. Ser frequentador de uma sala de integração e recursos. In: VI Sepesq - UNIRITTER: Porto Alegre. Anais do VI Sepesq, p. 1-10, 2010.

TAGER-Flusberg, H., \& SULLIVAN, K. Attributing mental states to story characters: a comparison of narratives produced by autistic and mentally retarded individuals. Applied Psycholinguistics, v. 16, p. 241-256, 1995.

TARDIF, M. Saberes docentes e formação profissional. 8.ed. Tradução de Francisco Pereira. Petrópolis-RJ: Vozes, 2007.

TOMASELLO, M. Origens culturais da aquisição do conhecimento humano. São Paulo: Martins Fontes, 2003.

VYGOTSKY, L.S. A Formação Social da Mente. São Paulo: Martins Fontes, 1998. 
WALTER, C. A adaptação do sistema PECS de comunicação para o Brasil: uma comunicação alternativa para pessoas com autismo infantil. In: Marquezine MC, Almeida MA, Tanaka EDO, Mori N, Shimazaki, E., organizadores. Perspectivas multidiciplinares em Educação Especial. Londrina: Ed. UEL, 1998, p.277-80.

WALTER, C. O PECS adaptado no ensino regular: ma opção de comunicação alternativa para alunos com autismo. In: NUNES, L. QUITERIO, P; WALTER, C.; SCHIMER, C.; BRAUN, P.(Org.) Comunicar é preciso: em busca das melhores práticas na educação do aluno com deficiência. Marilia: ABPEE, 2011, p. 127-140.

WALTER, C. Os efeitos da adaptação do PECS associada ao Curriculum funcional em pessoas com autismo infantil. Dissertação. São Carlos: São Paulo. Universidade Federal de São Carlos: 2000.

WERTSCH,J. La Mente en Acción. Buenos Aires: Aique, 1999.

\section{Notas}

'Entre os principais programas e ações do MEC podemos citar: Programa Educação Inclusiva: direito à diversidade; Programa Escola Acessível; Programa de Implantação de Salas de Recursos Multifuncionais; Rede de Formação Continuada de Professores na Educação Especial; Programa BPC na Escola, dentre outros.

${ }^{2}$ Entre os principais, encontra-se o Programa Nacional de Tecnologia Educacional (ProInfo) cujo objetivo é promover o uso pedagógico da informática na rede pública de educação básica.

${ }^{3}$ Como o atual Programa Nacional de Formação Continuada em Tecnologia Educacional (ProInfo Integrado), programa de formação voltada para o uso didático-pedagógico das Tecnologias da Informação e Comunicação (TIC) no cotidiano escolar

${ }^{4}$ Resultados dessas pesquisas podem ser vistas no Portal Nacional de Tecnologia Assistiva (http://www.assistiva. org.br/).

${ }^{5}$ Picture Exchange Communication System

${ }^{6}$ Entende-se mediação, desde uma perspectiva sócio-histórica, como uma cena de atenção conjunta e compartilhada entre dois ou mais sujeitos, que utilizam intencionalmente instrumentos e signos para promover um processo de apropriação com responsabilidade e competência diferenciada entre os participantes.

${ }^{7}$ No trabalho, nos referiremos ao programa somente por SCALA, utilizando a denominação Sistema SCALA quando referenciamos ao conjunto interdepentente de programa+metodologia.

${ }^{8}$ Desenvolvido sob licença GNUe Creative Commons para conteúdo aberto. O aplicativo para dispositivos móveis foi desenvolvimento para plataforma Android 3.0 e a versão web, em linguagem PHP5 e Javascript.

${ }^{9}$ Os símbolos pictográficos utilizados são propriedade de CATEDU (http://catedu.es/arasaac/) sob a licença Creative Commons e foram criados por Sergio Palao.

${ }^{10}$ Explicações detalhadas do sistema podem ser encontradas em: http://scala.ufrgs.br/

${ }^{11}$ Importante destacar que não consideramos aqui o contexto cultural como um meio que "cerce" o indivíduo, mas sim, como um elemento que configura a relação do indivíduo e o constitui.

${ }^{12}$ Quatro tipos de tempo: a) o tempo presente, que é o tempo microgenético, esse tempo de agora; b) o tempo vivido, que é o tempo da história enquanto ser humano, é o tempo ontogenêtico; c) o tempo histórico tem haver com a trajetória pessoal de vida de cada indivíduo, relacionado com a cultura; d) o tempo futuro, que é a projeção, expectativas próprias e dos outros, desejos, intenções futuras enquanto ser. Esses quatro tempos atravessam os contextos e se atualizam constantemente e precisam ser levados em conta quando projetos sistemas de tecnologia assistiva.

${ }^{13}$ É a ação desenvolvida pelas pessoas em interação social, apropriando-se dos instrumentos de mediação, e com a finalidade de modificar seu comportamento ou de outras pessoas ou modificar o meio (WERTSCH, 1999).

${ }^{14}$ A DSM V terá seu lançamento oficial em maio de 2013.

${ }^{15}$ Não faremos um levantamento do estado da arte das pesquisas na área de autismo, mas apresentaremos algumas pesquisas sobre desenvolvimento da linguagem e da comunicação, sem visar comparativos. 
${ }^{16}$ A comunicação funcional surgiu na década de 90 e propôs um sistema denominado Imagem Comunicação Exchange System (PECS), cujo objetivo é incentivar a comunicação espontânea, a partir do uso de reforçadores potenciais com imagens e trocas físicas, organizado em seis níveis hierárquicos.

${ }^{17} \mathrm{MEC}$ em parceria com a Universidade Aberta do Brasil - UAB promove o Programa de Formação Continuada de Professores para o Atendimento Educacional Especializado.

${ }^{18}$ Foi utilizado o ambiente Pbworks para disponibilização de materiais, atividades e mais uma sala de videoconferência.

${ }^{19}$ http://www.pbworks.com

\section{Correspondência}

Liliana Maria Passerino - Universidade Federal do Rio Grande do Sul, Faculdade de Educação, Departamento de Estudos Especializados. Av. Paulo Gama, 110 - prédio 12105, Centro, CEP: 90040-060 - Porto Alegre, Rio Grande do Sul - Brasil.

E-mail: lpasserino@gmail.com - bezrosangela@gmail.com - rosa@inf.ufrgs.br

Recebido em 08 maio de 2013

Aprovado em 18 de julho de 2013 
